\title{
Complementarity effects through dietary mixing enhance the performance of a generalist insect herbivore
}

\author{
Sybille B. Unsicker · Anett Oswald • \\ Günter Köhler · Wolfgang W. Weisser
}

Received: 29 October 2007 / Accepted: 10 January 2008/Published online: 27 February 2008

(C) Springer-Verlag 2008

\begin{abstract}
The ontogenetic niche concept predicts that resource use depends on an organism's developmental stage. This concept has been investigated primarily in animals that show differing resource use strategies as juveniles and as adults, such as amphibians. We studied resource use and performance in the grasshopper Chorthippus parallelus (Orthoptera, Acrididae) provided with food plant mixtures of either one, three or eight plant species throughout their development. C. parallelus survival and fecundity was highest in the food plant mixture with eight plant species and lowest in the treatments where only one single plant species was offered as food. C. parallelus' consumption throughout its ontogeny depended on sex, and feeding on different plant species was dependent on a grasshopper's developmental stage. To depict grasshopper foraging in food plant mixtures compared to foraging on single plant species, we introduce the term "relative forage total" (RFT) based on an approach used in biodiversity research by Loreau and Hector (Nature 413:548-274, 2001). RFT of grasshoppers in food plant mixtures was always higher than what would have been expected from foraging in monocultures. The increase in
\end{abstract}

Communicated by Thomas Hoffmeister.

Electronic supplementary material The online version of this article (doi:10.1007/s00442-008-0973-6) contains supplementary material, which is available to authorized users.

S. B. Unsicker · A. Oswald · G. Köhler · W. W. Weisser Institute of Ecology, University of Jena, Dornburgerstrasse 159, 07743 Jena, Germany

S. B. Unsicker $(\bowtie)$

Department of Biochemistry, Max Planck Institute for Chemical

Ecology, Hans-Knöll Strasse 8, 07745 Jena, Germany

e-mail: sunsicker@ice.mpg.de food consumption was due to an overall increase in feeding on plant species in mixtures compared to consumption of the same species offered as a single diet. Thus we argue that grasshopper foraging exhibits complementarity effects. Our results reinforce the necessity to consider development-related changes in insect herbivore feeding. Thorough information on the feeding ontogeny of insect herbivores could not only elucidate their nutritional ecology but also help to shed light on their functional role in plant communities.

Keywords Complementarity effect - Ontogenetic niche · Reciprocal feeding experiment - Relative forage total . Selection effect

\section{Introduction}

Dietary mixing in phytophagous insects has been the focus of various studies in the past decades (Bernays and Bright 1993; Bernays et al. 1994, 1997; Miura and Ohsaki 2006; Mody et al. 2007). In the majority of these studies, dietary mixing was found to positively affect the performance of generalist herbivores (Bernays and Bright 1993; Berner et al. 2005; Hägele and Rowell-Rahier 1999; Miura and Ohsaki 2004) although the underlying mechanisms are not totally clear. There are two older hypotheses for mixing behaviour in generalist herbivores. The nutrient complementation hypothesis assumes that single plant species rarely contain all the nutrients necessary for herbivore growth, and postulates that by broadening the diet, herbivores are more likely to obtain a full complement of essential nutrients (Pulliam 1975; Rapport 1980). A number of studies have found compensatory feeding in insect herbivores as predicted by this theory (Berner et al. 
2005; Lee et al. 2004; Takeuchi et al. 2005). The toxin dilution hypothesis states that by dietary mixing individual toxins produced by particular plant species are consumed at a lower dosage which therefore lessens their effect (Behmer et al. 2002; Freeland and Janzen 1974; Marsh et al. 2006; Singer et al. 2002). More recently, Raubenheimer and Simpson developed a geometric model of feeding for generalist insects that allows an exploration of how the intake of dietary protein, carbohydrate and salts affects herbivore development (see review by Raubenheimer and Simpson 1999), and based on this approach, a number of studies have shown that herbivores generally have to balance their intake of different nutrients for successful development (Behmer and Joern 1993; Berner et al. 2005; Lee et al. 2002).

So far, a shortcoming in most studies on dietary mixing in generalist insect herbivores is that they have often been restricted to one particular developmental stage rather than observing the complete ontogeny of insects with respect to food plant use. It is conceivable that as generalist insects grow and thus change morphologically and physiologically, they might change their food plant species in order to meet their nutritional requirements. Werner and Gilliam (1984) proposed the concept of the ontogenetic niche to address such patterns of resource and habitat use that can change when an organism grows. "The ontogenetic niche offers a temporal perspective of variation in [...] resource use that can direct investigation toward life stages in which specialization and the propensity for resource-associated adaptation is most likely" (Dopman et al. 2002). Such ontogenetic niches have been reported for a variety of groups of organisms with respect to both resource and habitat use. For example, in amphibians, tadpoles are restricted to aquatic habitats while adults of many species are largely terrestrial.

Ontogenetic shifts may, however, also be more subtle. In paurometabolous insects such as grasshoppers, the different nymphal stages and the adult feed in the same habitat and on the same type of food, i.e. herbaceous plants, but nevertheless there can be changes in host plant preferences. In an experiment by Sword and Dopman (1999), the generalist grasshopper Schistocerca emarginata showed a developmental shift in resource breadth, with narrow diet breadth as juveniles and true polyphagous feeding patterns as adults. This study gives an indication that a certain mix of plant species might meet the requirements of generalist herbivores only at a particular time during their development but may not be appropriate for all developmental stages. Host-plant switches during the development might not only happen as a result of the insects' morphology and physiology but also because of spatial and temporal changes of food plant quality (Hellmann 2002; Scriber and Slansky 1981). Furthermore, there may be sex-related differences in nutritional requirements. Females most often gain higher weight as adults and have thus an overall higher need for food. Whether the composition of food plants differs between the sexes throughout their development remains unclear. Information about shifts in foraging strategies of herbivorous insects related to their ontogeny and sex-dependent feeding preferences is necessary in order to detect adaptive feeding behaviour in heterogeneous environments.

The aim of this study was to deduce food plant use and feeding patterns of the meadow grasshopper Chorthippus parallelus (Zetterstedt, 1821) from hatching to death in food plant monocultures and mixtures. $C$. parallelus is one of the most common grasshopper species in Central Europe (Ingrisch and Köhler 1998) and earlier studies on its feeding preferences have shown that its diet mainly consists of grasses (Poaceae), but that some forbs and legumes are also accepted as food plants (Bernays and Chapman 1970a, b; Gardiner and Hill 2004; Kaufmann 1965; Unsicker 2006). In order to study consumption of $C$. parallelus in mixtures, we modified an approach by Loreau and Hector (2001) which is frequently used in the biodiversity literature to compare productivity in plant species mixtures versus monocultures (e.g. Roscher et al. 2005). This approach allowed us to test the feeding response of the herbivore to a broader diet in a quantitative way. In particular, when not only the diversity of food plants in the diet increases, but also the total amount of plant material ingested, this increase in consumption may be achieved either by increased ingestion of those plants that are also predominantly eaten when offered on their own, or by a general increase in consumption of all plant species, compared to consumption of the single species diets. The first mechanism is called selection effect (SE) in the biodiversity literature whereas the latter one is referred to as complementarity effect (CE) (Hector et al. 2002).

The main questions we asked in this study were:

1. Does dietary mixing result in a fitness increase in the meadow grasshopper?

2. Are there specific resource use strategies in $C$. parallelus in relation to developmental stage?

3. Does resource consumption increase in mixtures and is this increase due to the CE or the SE?

4. Are there different feeding strategies in male and female grasshoppers?

\section{Materials and methods}

Study organism

Chorthippus parallelus (Zetterstedt, 1821, Orthoptera, Acrididae) is a univoltine grasshopper species of the 
subfamily Gomphocerinae. It has a widespread distribution and occurs in many habitat types throughout Central Europe (Köhler 2001). Grasshoppers that were used for this experiment were the offspring of adult females caught in late August 2003 in a species-rich (32 plant species on average in four $1-\mathrm{m}^{2}$ relevés) extensively managed mountain meadow in the Franconian Forest, Germany $\left(50^{\circ} 23^{\prime} \mathrm{N}, 11^{\circ} 26^{\prime} \mathrm{E}\right)$. At this time of year, $C$. parallelus was the most abundant grasshopper species in the area (Köhler and Renker 2004). The females oviposited in the lab in a 50/50 mixture of moistened sand and soil. Egg clutches were kept at room temperature for 2 weeks, allowing the embryos to develop, and then transferred to the refrigerator where they overwintered at $5^{\circ} \mathrm{C}$ until the start of the experiment in July 2004.

\section{Food plants}

Eight food plants were selected for this study, four grass species (Anthoxanthum odoratum, Dactylis glomerata, Holcus lanatus and Trisetum flavescens), three forbs (Geranium sylvaticum, Plantago lanceolata and Taraxacum officinale) and one legume (Trifolium pratense). In the remainder of this paper only the genus name of food plant species will be given. The plant selection was based on an intensive literature survey on potential food plants of C. parallelus (Table S1 in Electronic supplementary material) and on the occurrence and abundance of these potential food plants in the habitat where the female grasshoppers were caught in 2003. We selected both plant species that were judged "very suitable" and also some that were judged "less suitable" in the literature (see Table S1). Based on this assessment, we hypothesized a quality ranking for the food plants. Plants were offered to $C$. parallelus singly in the onefood treatment, in mixtures of three plants (three-foods treatment), and as a mixture of all plants (eight-foods treatment). Table 1 shows a list of the different food plant treatments. There were eight treatments where single food plants were offered, six treatments with three species in a mixture and one treatment where all plant species were offered in a mixture. The three-foods treatments were not the result of a random draw of plant species, but were chosen to represent particular food plant combinations (Table 1).

\section{Rearing experiment}

At the end of July 2004, forty-four egg pods were removed from the refrigerator and separated in plastic cups $(4.5 \times 9.5 \mathrm{~cm})$ that were half filled with a 50/50 mixture of moistened sand and soil. Each cup was covered with plastic mesh to prevent freshly hatched grasshopper nymphs from escaping. All egg pods were placed in a climate chamber at $20^{\circ} \mathrm{C}$ room temperature and $16 / 8 \mathrm{~h}$ light/dark cycle. Within 14 days all grasshoppers had hatched from the egg pods. After hatching each individual nymph was isolated in a small plastic cup where freshly cut wheat leaves (Triticum aestivum) were provided as a food resource until the start of the experiment. Hatchlings fed for up to 3 days on wheat leaves before they were assigned to their individual treatment.

Grasshoppers were reared individually from the first instar to death in 6-1 plastic boxes (Faunabox, $27 \times 18 \times 18 \mathrm{~cm}$; Savic, Belgium) where they were subjected to one of the 15 food plant treatments (Table 1). Ten grasshoppers were used for each treatment except for the mixture with eight plant species where there were 50 replicates (Table 1), resulting in 190 grasshopper individuals in total. The plastic boxes with the grasshoppers were placed outdoors on a wooden shelf-unit partitioned into ten blocks to account for variation in microclimatic conditions. Each block contained 19 boxes, one box for each one-food treatment as well as one box for each three-foods treatment and five boxes for the eight-foods treatment. The position of the boxes within a block was rotated within each block every time grasshopper feeding was recorded. In days with high temperature and sunshine, the boxes on the shelf-unit were shaded with a white sheet.

All food plants were placed in plastic cups that were filled with water, and covered tightly with Parafilm, leaving only a small hole for the plant, to prevent the grasshoppers from drowning and plants from desiccation. Every third day, food plants were exchanged for freshly cut plant individuals and the consumption of each plant species was quantified (see below). The food plants for this experiment were always collected at the same meadows. For grasses, individual tillers were offered. For forbs and legumes, individual leaves were taken. Templates for the various size classes of leaves from the different food plants were drawn on paper (from ten to 15 paper templates for leaves of each food plant species), and these templates were consecutively numbered for each plant species. Food plants in the cages were controlled daily to ensure a sufficient supply of each plant species at any time throughout the experiment. Whenever necessary, food plants were replenished. Thus, food was provided ad libitum from each of the plant species included in the particular treatments to ensure that grasshoppers could feed exclusively on any one plant species.

Variables measured

To measure consumption, leaf area loss due to grasshopper feeding was measured every third day when the food plants 
Table 1 Food plants and food plant combinations in mixtures of the reciprocal feeding experiment

\begin{tabular}{llll}
\hline Treatment & Quality valuation $^{\mathrm{a}}$ & Plant species & $n$ \\
\hline $\begin{array}{c}\text { One-food } \\
\text { treatments }\end{array}$ & & & \\
Grasses & Low & Anthoxanthum odoratum & 10 \\
& High & Dactylis glomerata & 10 \\
& High & Holcus lanatus & 10 \\
& Medium & Trisetum flavescens & 10 \\
Forbs & Low & Geranium sylvaticum & 10 \\
& Low & Plantago lanceolata & 10 \\
& Medium & Taraxacum officinale & 10 \\
& High & Trifolium pratense & 10
\end{tabular}

Three-foods mixtures
High-quality grass mixture

High-quality grasses and forb

High-quality grass, low-quality forbs

Low-quality forb mixture

Low-quality grass, low-quality forbs

High-quality forb mixture
D. glomerata, H. lanatus, T. flavescens 10

D. glomerata, H. lanatus, T. pratense $\quad 10$

D. glomerata, G. sylvaticum P. lanceolata 10

G. sylvaticum, P. lanceolata, T. officinale 10

A. odoratum, G. sylvaticum, P. lanceolata 10

P. lanceolata, Taraxacum officinale, $\quad 10$ Trifolium pratense

Eight-foods mixture
${ }^{\text {a }}$ Based on a literature survey (Table S1 in Electronic supplementary material) and the expertise of G. Köhler
All eight plant species were exchanged. The leaf area removed was quantified with graph paper in square millimetres. The area of plant individuals that was completely eaten, e.g. grass blades, was reconstructed using the paper templates (explained in the previous paragraph). The developmental stage of each grasshopper was noted every time consumption was quantified. When the grasshopper individuals were about to moult into the adult stage all cages were monitored daily to determine the exact moulting dates. The average dry weight of leaves of all food plants offered in the experiment was determined by cutting $1-\mathrm{cm}^{2}$ discs of 30 individuals of each species, drying them for $48 \mathrm{~h}$ at $70^{\circ} \mathrm{C}$, and weighing them. In this way the biomass consumed by each grasshopper could be calculated. Grasshopper sex was determined when individuals reached nymphal stage three (L3). For all individuals that died before that time, sex was determined in dead animals with the help of a microscope.

Fresh weight of all 190 grasshoppers was measured in the first instar (L1), just before the experiment started, 3 days after they reached maturity and at the time of death independent of the age. After the grasshoppers died, they were stored in $70 \%$ ethanol until dry weights were measured. All grasshoppers were dried to a constant weight in the drying oven at $70^{\circ} \mathrm{C}$. The date when grasshoppers reached maturity was recorded to calculate the time of nymphal development for each individual.

To measure female fecundity, each female grasshopper was allowed to mate with one male for $24 \mathrm{~h}$ five days after the maturity moult. Males were taken from a stock culture that consisted of a subset of the hatchlings for the experiment and maintained on wheat plants outdoors until they were used as mating partners in the experiment. For oviposition, each female grasshopper was provided with a small plastic cup in its box filled with a moistened sand/soil mixture (50/50). After the termination of the experiment the egg pods laid by each female grasshopper were counted.

\section{Consumption in monocultures and mixtures}

In order to analyse plant consumption in mixtures, we used measures from agricultural and biodiversity research that were developed to quantify effects of increasing biomass production in species mixtures as compared to the monocultures (overyielding, e.g. Hector et al. 2002). A frequently used quantity for overyielding is relative yield total (RYT) (Connolly 1986; Hooper 1998) which measures whether the productivity (biomass production) of a plant in a mixture is more or less than expected from the productivity in monoculture. We can use this theory by taking grasshopper consumption of plants in monocultures and mixtures as the dependent variable. Instead of RYT we therefore calculated "relative forage total" (RFT) to quantify consumption in mixtures. In the context of this study, the relative forage of species $i\left(\mathrm{RF}_{i}\right)$ compares the 
observed consumption by the grasshopper of plant species $i$ in a mixture $\left(C_{i}\right)$ with grasshopper consumption of this plant species in monoculture $\left(M_{i}\right)$ (de Wit and van den Bergh 1965; Trenbath 1974), i.e.

$\mathrm{RF}_{i}=C_{i} / M_{i}$

RFT is then defined as the sum of the relative forage of all component species of the mixture, where $n$ is the total number of species in the mixture:

$\mathrm{RFT}=\sum_{i=1}^{n} \mathrm{RF}_{i}$

RFT $>1$ (overyielding) indicates that the proportional increase in the consumption of one or several species overcompensates for the possible co-occurring proportional decreases in consumption of other species in the mixture. To analyse the consumption of a particular species, we can calculate:

$V_{i}=n \times \mathrm{RF}_{i}$

as the ratio of observed to expected relative forage, the latter simply being the frequency of a plant species in mixture, i.e. $1 / n$. If $V_{i}>1$, the plant species is consumed more in the mixture than expected from the monoculture; if $V_{i}=1$, then the plant species is consumed identically in mixture and monoculture. Finally, if $V_{i}<1$, there is less consumption of species $i$ in the mixture than expected from the monoculture.

To further analyse the source of any increase in productivity Loreau and Hector (2001) introduced the concept of additive partitioning. We apply this concept to the analysis of grasshopper consumption and define, analogous to Loreau and Hector (2001) a SE and a CE that account for differences in consumption between monocultures and mixtures, using the following equations:

$\mathrm{CE}=n \times \overline{\Delta R C} \times \bar{M}$

and

$\mathrm{SE}=n \times \operatorname{cov}(\Delta R C, M)$

where $n$ is the number of species in the mixture and $\Delta \mathrm{RC}_{i}=\mathrm{RF}_{i}-(1 / n)$ is the deviation from the expected relative forage of species $i$ in the mixture. For $\mathrm{CE}$, the means over all species of $\Delta \mathrm{RC}_{i}$ and $M_{i}$ are computed, and for $\mathrm{SE}$, the covariance between the $\Delta \mathrm{RC}_{i}$ and $M_{i}$ is considered. The SE measures whether plant species that are consumed in great quantities in the monocultures also have a high relative yield in mixtures, i.e. if there is a positive $(\mathrm{SE}>0)$ or negative $(\mathrm{SE}<0)$ covariance among species between the consumption in the monoculture and the relative yield in the mixture. When the SE is zero, than there is no relationship between the consumption in the monoculture and the relative forage in mixtures. In contrast, the
CE measures the change in average relative forage of the species. $\mathrm{CE}$ is positive when the average relative forage increases, i. e. when plant species are, on average, consumed more in mixtures than expected from the monoculture feeding trials. The net biodiversity effect $(\mathrm{NE})=\mathrm{CE}+\mathrm{SE}$ is then the difference between observed and expected consumption, i.e. if $\mathrm{NE}>0$, the observed consumption in the mixture is greater than expected from the monocultures. We calculated RFT, $V_{i}, \mathrm{RF}_{i}$ and NE, SE and $\mathrm{CE}$ for each mixture and each nymphal stage of the grasshopper to analyse consumption in the mixtures, based upon the consumption of the nymphal stages in the onefood treatments.

\section{Statistical analysis}

To test the effects of grasshopper sex, the number of food plant species and the identity of the food plant mixture on grasshopper fitness, general linear models were performed in SPSS 13.0 for Windows. Food plant mixture was nested in the number of food plants for the analysis. Whenever grasshopper sex was included in the ANOVA, sex was fitted before the interaction term (number of food plant species $\times$ food plant mixture). For the analysis of feeding patterns as a function of developmental stage in the eightfoods mixture, repeated measures ANOVAs were performed. All statistical assumptions, such as normal distribution and homoscedasticity were checked and count data (number of egg pods laid by each female) were square-root transformed prior to analysis. Means are always displayed with standard errors. Type-I sums of squares were used throughout this paper.

\section{Results}

\section{Grasshopper performance}

The sex ratio in the reciprocal feeding experiment with C. parallelus was almost 1, with 96 (50.53\%) males and 94 (49.47\%) females (Table S2 in Electronic supplementary material). The survival of $C$. parallelus was best in the eight-foods mixture, followed by the three-foods mixtures. In most one-food treatments, survival was very low (Fig. 1a, b). Survival in males and females did not differ but there were significant differences in the lifespan of grasshoppers feeding in the treatments with different numbers of food plant species (ANOVA number of food plant species: $F_{2,12}=88.62 ; P<0.001$, sex $F_{1,172}=$ $0.27 ; P=0.61)$. The majority of grasshoppers that did not reach maturity died in nymphal stage one and two $(53.1 \%$, Fig. 1c). Only $7.9 \%$ of the grasshoppers died in the third 
Fig. 1 a Survival of Chorthippus parallelus grasshoppers in the reciprocal feeding experiment with one, three and eight plant species. Numbers above bars indicate the number of grasshoppers analysed. Bars represent means \pm standard error. b Survival of $C$. parallelus grasshoppers in the 15 individual treatments. Bars represent means \pm standard error. c Developmental stage of C. parallelus at death in the 15 different treatments: striped bars first instar, black bars second instar, dark grey bars third instar, light grey bars fourth instar, white bars mature

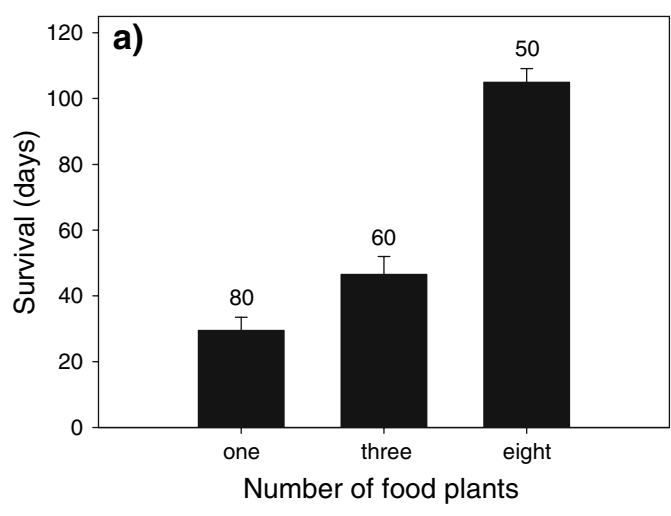

b)
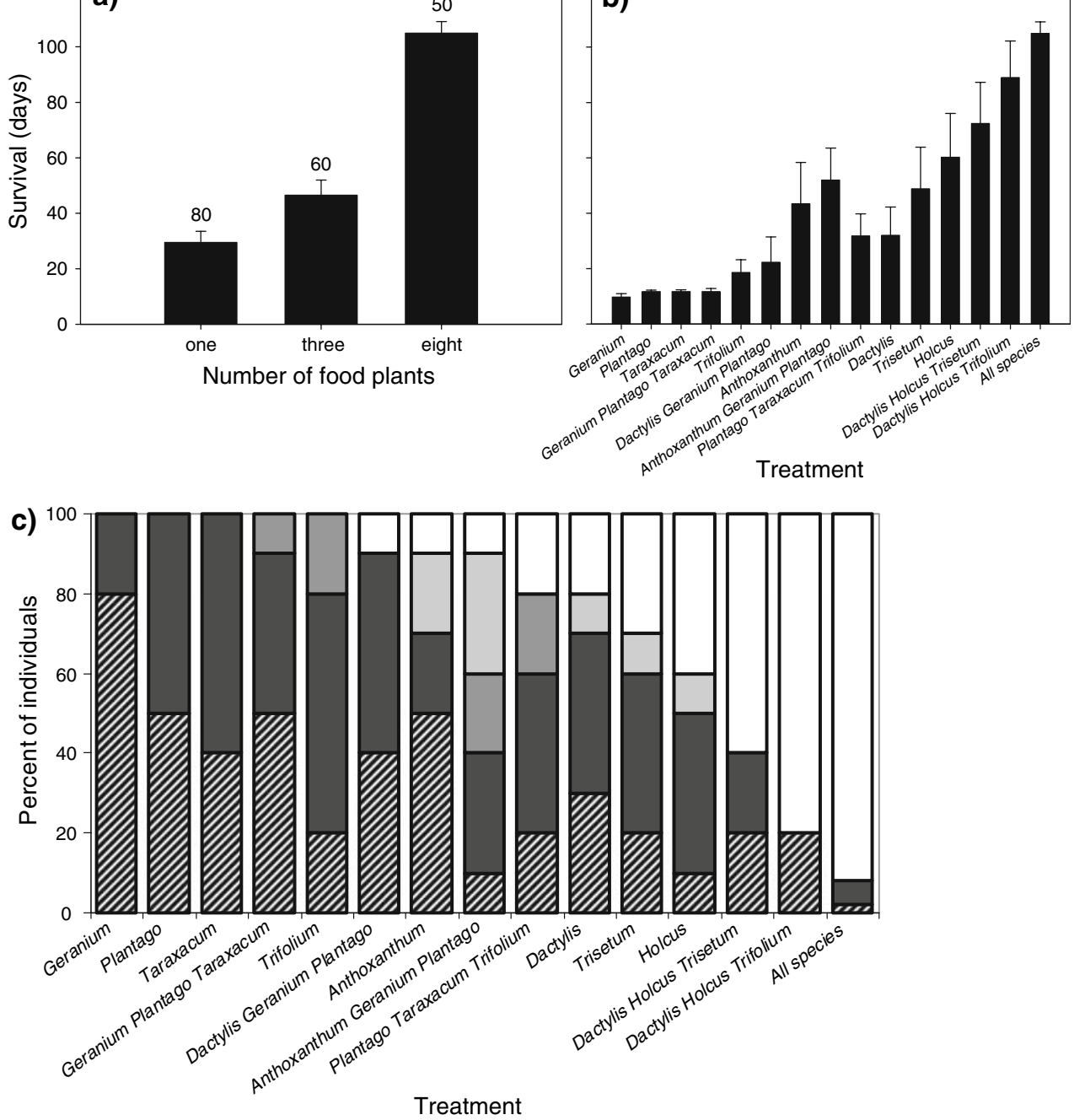

and the fourth instar; $38.9 \%$ survived until maturity (Fig. 1c). None of the grasshoppers reached maturity in the four-forbs monocultures and in the three-foods mixture with Geranium, Plantago and Taraxacum (Fig. 1c). Only $8 \%$ of the 50 individuals in the eight-foods mixture died before they reached maturity.

Mean developmental time from hatching to adulthood for all 74 grasshoppers that reached maturity was $51.09 \pm 0.77$ days. There were no differences in developmental time between the three food plant diversity levels and between male and female grasshoppers (ANOVA number of food plant species: $F_{2,7}=1.12 ; P=0.33$, sex $\left.F_{1,61}=0.82, P=0.37\right)$. The fresh weight of newly hatched L1 larvae did not differ but the fresh weight 3 days after the maturity molt significantly differed between males and females and between the three food plant diversity levels (ANOVA number of food plant species: $F_{2,7}=11.91 ; P<0.001$, sex $\left.F_{1,57}=161.87, P<0.001\right)$ with individuals of the eight-foods mixture reaching the highest weight.
The number of egg pods laid per female grasshopper was on average $0.84 \pm 0.16$ in the eight-foods treatment, $0.39 \pm 0.17$ in the three-foods treatment and $0.05 \pm 0.05$ in one-food treatments (ANOVA $F_{2,12}=4.82, P=0.03$ ).

Feeding ontogeny in the eight-foods mixture

The eight-foods mixture showed that there were clear preferences of $C$. parallelus for some food plant species. Five of the plant species offered in the eight-foods treatment were consumed throughout the development of $C$. parallelus, but in different total amounts (Fig. 2a). Foraging on the three herbaceous plant species Geranium, Taraxacum and Plantago was negligible, but consumption of the legume Trifolium was considerable. The lifetime consumption of plant tissue by females was $102.14 \pm 3.27 \mathrm{mg}$ on average, which was significantly more than the consumption of $75.15 \pm 2.06 \mathrm{mg}$ by males (ANOVA plant species, $F_{1,7}=55.92, P<0.001$; sex 
$F_{7,352}=331.24, P<0.001$; Fig. 2 a). The fraction of each plant species in the diet changed systematically during the development of $C$. parallelus (Fig. 2b, results of the repeated measures ANOVA shown in Table 2). While consumption of Trisetum dominated in the first instar in male grasshoppers, it decreased with age to around $10 \%$ of total food intake in the adult stage. In females, consumption of Trisetum also decreased from around $20 \%$ in the first instar to $10 \%$ in the adult stage. In contrast, the proportion of Holcus was low in the diet of first instar grasshoppers, but the proportion increased with developmental stage. Trifolium and Anthoxanthum were consumed at a fairly constant rate throughout all developmental stages in both male and female grasshoppers. Thus, in the generalist herbivore $C$. parallelus both sex and developmental stage affected host plant preferences.

\section{Food consumption}

We calculated $V_{i}$ (observed over expected forage), NE, SE and $\mathrm{CE}$ for those plant species and nymphal stages where monoculture consumption was available. Thus, for the first instar, NE, SE, and CE could be calculated for all mixtures as feeding on all plant species was measured in monoculture, but the number decreased to two species (Holcus and Trisetum) for females, respectively, and to four species (Anthoxanthum, Dactylis, Holcus, Trisetum) for males in the adult stage.

RFT was significantly greater than one for all nymphal stages in the eight-foods mixture and most three-foods mixtures, indicating higher than expected consumption in the mixtures compared to the average one-food treatment (Fig. 3).

For both females and males $V_{i}$, i.e. observed over expected relative forage were significantly greater than one for Anthoxanthum, Dactylis, Holcus, Trisetum in all instars wherever they could be calculated (in females $V_{i}$ could not be calculated for Anthoxanthum and Dactylis in the adult stage, Fig. S3 in Electronic supplementary material). For Trifolium, $V_{i}$ was significantly greater than one in males and females wherever it could be calculated (males instars one to three, females instar one and two, Fig. S3 in Electronic supplementary material). For Plantago, Geranium and Taraxacum, $V_{i}$ could not be calculated due to the high mortality of grasshoppers in monocultures of these plants. Thus, for all plants for which it could be calculated, consumption was higher than expected from consumption in the monocultures

The NE in the eight-foods mixture was significantly greater than zero in all nymphal stages and was highest in nymphal instar four (Fig. 4). The SE was always smaller than zero (Fig. 4) and in most cases significantly so. Thus, the consumption of species in the monoculture was either not a good predictor of relative forage in the mixtures, or there was a negative covariance, i.e. for species which were heavily consumed when offered alone the relative forage was relatively small in mixtures whereas for species little consumed in monocultures the relative forage was higher than expected. In contrast, the $\mathrm{CE}$ was positive for all mixtures and in most cases significantly greater than zero (Fig. 4), showing that the average relative forage increased. Thus, total consumption of $C$. parallelus is higher in mixtures than when plants are offered as one food and the increase in total consumption is not just due to an increase in consumption of a few favoured plant species but consumption of all plants is stimulated, for those plants that were eaten at all.

\section{Discussion}

In the current study, we addressed the question whether dietary mixing is beneficial for the performance of the generalist grasshopper $C$. parallelus and if resource use strategies of males and females of this species vary with developmental stage and the number of food plant species present.

C. parallelus performed better in food plant mixtures than on single plant species and survival as well as fecundity were highest in the eight-foods mixture and lowest in the food plant monocultures. The developmental stage significantly influenced feeding patterns of $C$. parallelus individuals and RFT of mixtures was always higher than what would have been expected from forage in monocultures alone. This increase in RFT was due to an increase in consumption of all plant species rather than in just a few favoured species such that the CE explained most of the change of consumption in mixtures compared to monocultures.

Preference and performance for the different host plant species

Mixing appears to be obligatory for the meadow grasshopper $C$. parallelus, as there was less than $50 \%$ survival to maturity when only one plant species was offered as a food source. All eight plants species in the feeding experiment were among the most abundant plants from the site where the study population originated from, and they were reported in the literature as potential food plants for C. parallelus (Table $\mathrm{S} 1$ in Electronic supplementary material). Dactylis was most preferred by grasshoppers in the eight-foods mixture as measured by the amount of plant tissue consumed. Nevertheless, the consumption rates in 
Fig. 2 a Lifetime consumption of $C$. parallelus of the eight plant species in the eight-foods mixture. Bars represent means \pm standard error. b Proportion of plant species in the eight-foods mixture in relation to the total consumption of C. parallelus males (left-hand panel) and females (right-hand panel) in one particular developmental stage (larval instars one to four and the adult stage). Open circles Dactylis; closed circles Anthoxanthum; closed triangles Holcus; open triangles Trisetum; closed squares Trifolium; open squares Geranium, Plantago and Taraxacum combined
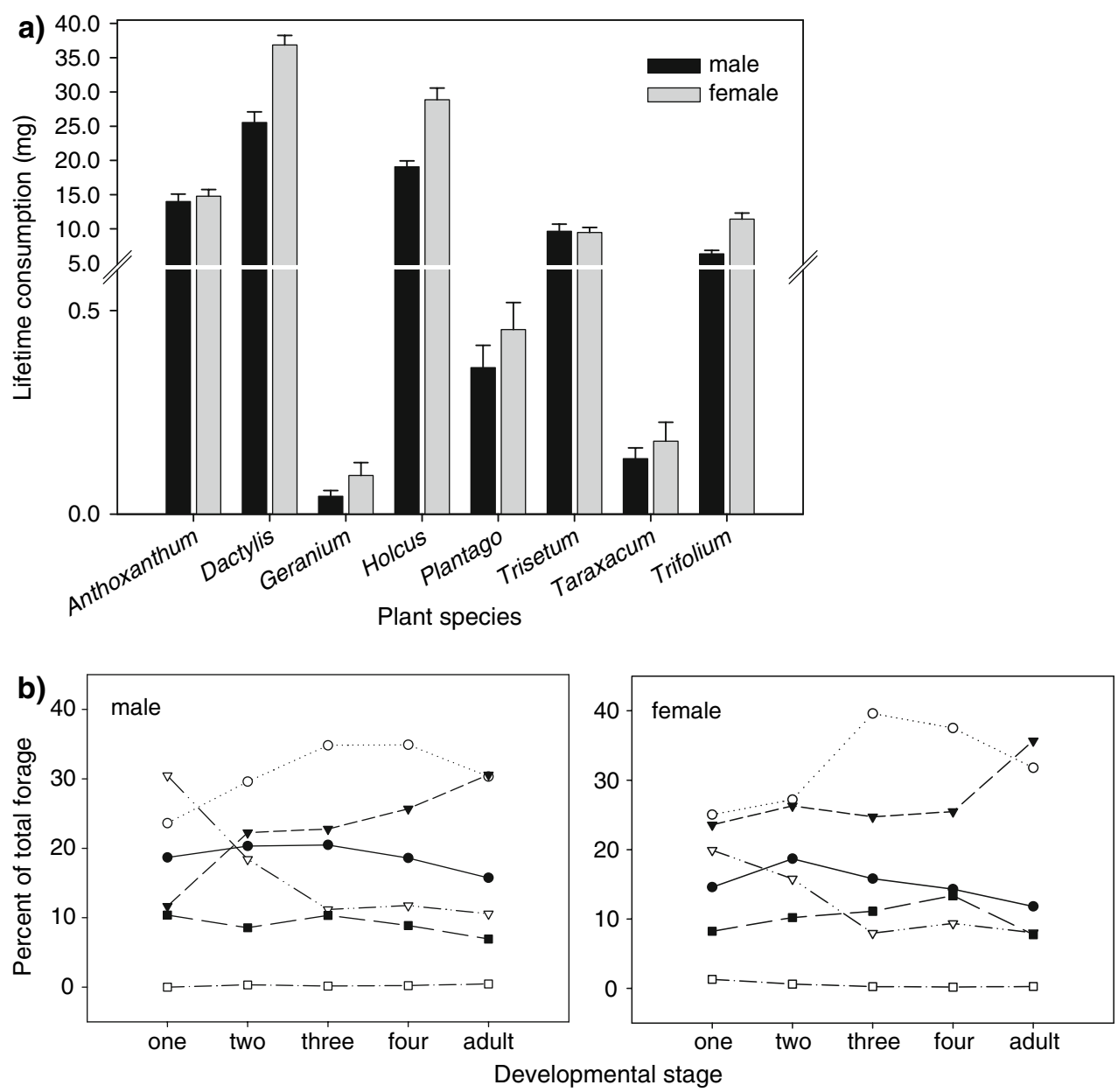

Table 2 Results of repeated measure ANOVAs for the percent consumption of individual food plants in the eight-foods mixture by male and female grasshoppers in five developmental stages

\begin{tabular}{llllllllll}
\hline \multicolumn{1}{c}{$d f$ (hypothesis, error) } & $F$-values $^{\mathrm{a}}$ & & & & & \\
\cline { 3 - 9 } & & Anthoxanthum & Dactylis & Geranium & Holcus & Plantago & Taraxacum & Trifolium & Trisetum \\
\hline Developmental stage & 4,41 & $4.0^{* *}$ & $7.760^{* * *}$ & $3.615^{*}$ & $14.882^{* * *}$ & 1.520 & $8.993^{* * *}$ & $4.088^{* *}$ & $3.752^{*}$ \\
Sex & 1,44 & 2.819 & 0.213 & 0.002 & 3.233 & 1.056 & 0.301 & 0.543 & $4.730^{*}$ \\
Sex $\times$ development & 4,41 & 0.50 & 0.684 & 1.168 & 1.262 & 1.980 & 1.455 & 0.984 & 0.259 \\
\hline
\end{tabular}

$* P<0.05 ; * * P<0.01 ; * * * P<0.001$

${ }^{\text {a }} F$-values are shown (Pillai's trace) for the entire development of grasshoppers

mixtures did not correspond to the performance on these plants when they were offered individually. As our experiment showed, grasshoppers reached maturity in mixtures that included at least one grass species but in the treatment with Dactylis as the only food plant, mortality before maturity was greater than $70 \%$. Survival on Dactylis alone was lower than survival on the two grass species Trisetum and Holcus. The quantity that is consumed by a particular plant species thus does not reflect plant quality. Thus grasshoppers may consume more biomass from a plant species that is a suboptimal food source to supply their needs in terms of nutrition and water (Berner et al. 2005).

The survival rate in the three-species mixture with Trifolium, Holcus and Dactylis was nearly as high as in the eight-foods mixture. Whenever the legume Trifolium was present in mixture, the grasshoppers fed on this plant at a relatively constant rate and in all developmental stages. Herbaceous legumes are known to be rich in nitrogen (Bernays and Chapman 1994), as their symbiosis with rhizobia allows them to fix atmospheric nitrogen. Nitrogen in turn is an essential nutrient for the development of 


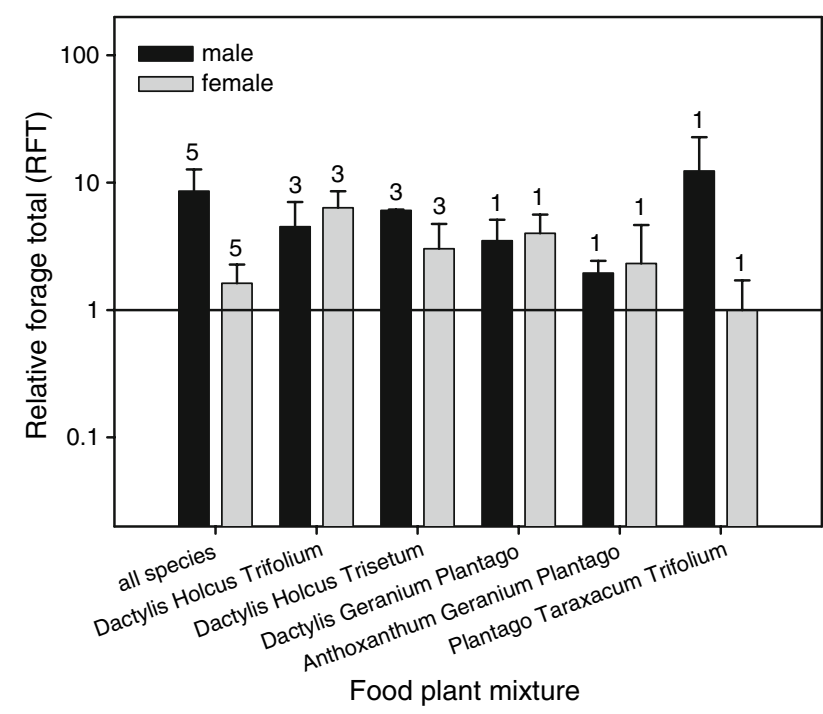

Fig. 3 Relative forage total (RFT) of first instar C. parallelus males and females in the eight-foods mixture and five three-species mixtures. Values greater than 1 (reference line) indicate a higher consumption of the mixture than expected from monoculture consumption. The numbers above the bars show the numbers of plant species used for the calculation of RFT. Bars represent means \pm standard error

grasshoppers (Chapman and Joern 1990). By feeding on the nitrogen-rich plant species Trifolium in addition to grass species which are rather poor in total nitrogen content, C. parallelus probably performed nutrient complementary feeding. Beneficial effects of legumes in mixtures with grasses on biomass gain of grasshoppers have been shown in a study by Pfisterer et al. (2003) on Parapleurus alliaceus in an experimental grassland site. $P$. alliaceus gained higher body mass in mixtures where legumes were present in addition to grasses (Pfisterer et al. 2003).

The ontogeny of feeding and sex-related differences

Observations from the eight-foods mixture in this study showed that there are differences between developmental stages in terms of the amount consumed of each plant species. The relative proportions of food plants changed over time in both males and females. The proportion consumed of Trisetum for example steadily decreased during ontogeny, whereas the proportion of Holcus consumed in each instar increased. Changes in feeding patterns could be due to morphological or physiological changes in the grasshoppers or to changes in the physical and chemical properties of the food plants in the course of the season. Feeding on Holcus might especially be difficult for early instar grasshoppers with small mandibles because of the hairy leaf surface (Bernays and Chapman 1970a). Trisetum was the most preferred grass of first instar males but consumption of this species steadily decreased until the grasshoppers reached maturity. In the third and fourth instar female grasshoppers consumed a higher proportion of the legume Trifolium than of the grass species Trisetum. Female grasshoppers have a higher need for nitrogen when they produce egg batches (Chapman and Joern 1990). Although there is only weak evidence from the literature that $C$. parallelus feeds on plants other than members of the Poaceae under natural conditions (Bernays and Chapman 1970b), we want to emphasize the fact that $10 \%$ of the diet of both males and females consisted of the legume $T$. pratense. This consumption rate was fairly constant in both sexes throughout the whole development (Fig. 2b). As the grasshoppers had the opportunity to feed exclusively on grasses at any time during the experiment but nevertheless fed on the legume, we consider $C$. parallelus (at least the population that we investigated in this study) as a generalist feeder rather than a specialist.

Feeding in mixture versus monoculture

Another important result of this study was that in the mixtures, grasshoppers consumed more tissue from individual plant species than would have been expected from the foraging of grasshoppers in the treatments where only one plant species was offered. In other words, there was "overforaging" in mixtures compared to plant monocultures as indicated in values of RFT above one throughout the development. Interestingly, most increase in consumption could be attributed to the $\mathrm{CE}$, i.e. a general stimulation of feeding on all plants. There are several conceivable reasons for this feeding behaviour. In the literature on generalist insect herbivores there is evidence that feeding behaviour of grasshoppers depends on the number of food plants present. Bernays and Bright (1993) noted that the generalist grasshopper species Taeniopoda eques regularly switched food plants and spent more time feeding when additional food plants were offered. Although not measured, a longer time spent feeding is likely to result in an increased consumption rate. Bernays and Bright (1993) suggested that the chemical novelty of each additional food plant stimulates feeding and leads to compulsive switching. Furthermore, they assume that "the situations in which arousal with novelty may be important in promoting mixing should be those in which insects live in complex habitats with very diverse potential food items" (Bernays and Bright 1993). An imbalance of nutrients or the presence of toxins that are deleterious for grasshoppers when consumed in excess might be an additional cause for a lower consumption rate of food in single-plant treatments versus mixtures. If one plant species alone does not meet the requirements of grasshopper nymphs in all 
Fig. 4 Net biodiversity effect, selection effect and complementarity effect in food consumption of $C$. parallelus in six different food plant mixtures in the first instar (left-hand panels) and for the entire grasshopper development (larval instars one to four and the adult stage, right-hand panels). Closed circles Males, open triangles females
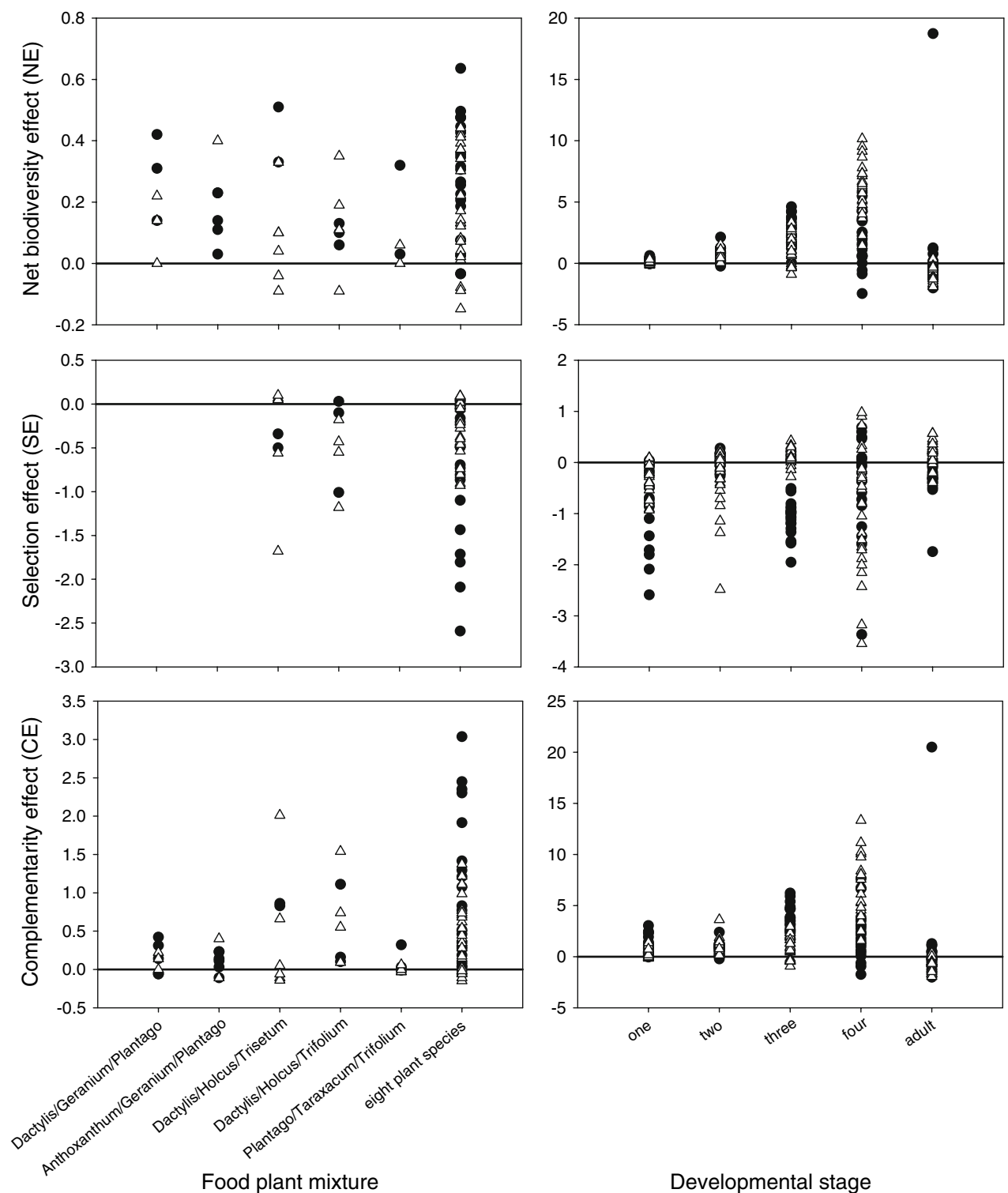

Developmental stage developmental stages, individuals presented with a mixture of food plants will always perform better as there is a higher chance of getting an optimal diet. Toxic compounds may either directly slow feeding rates or hinder nutritional acquisition (Joern 1996). In mixtures of food plant species, grasshoppers can dilute these toxins of single plants by switching to other food plants before the toxins reach deleterious levels in the hemolymph. In addition, a full complement of nutrients can better be gained by feeding on a variety of food plants, each of which has a certain nutrient ratio.

\section{Conclusion}

Although a variety of studies in the past have shown that there are beneficial effects of dietary mixing on generalist grasshoppers, our study demonstrates that there are changes in food preference in relation to the developmental stage and sex. Thus, it is essential to consider the ontogenetic niche with respect to feeding behaviour in order to predict the effect of different plant communities on insect herbivores. Furthermore, by applying the procedure of additive partitioning of biodiversity effects proposed by Loreau and Hector (2001) to grasshopper feeding behaviour we could show that in dietary mixing the different food plants act in a complementary manner, i.e. the presence of a diversity of food plants stimulates feeding on all suitable plants. The results of this study suggest that resource use strategies and food plant shifts related to ontogeny and sex should be considered in future experiments assessing the importance of particular food plants for the performance of generalist insect herbivores. 
Acknowledgments We want to thank Ronald Enke and Rainer Enke who constructed and built the rack for the grasshopper cages, Ilka Egerer for her help during the experiment, and Christoph Scherber and Jens Schumacher for statistical advice. We thank Thomas Hoffmeister and one anonymous reviewer for comments on the manuscript. The project was funded by BMBF BIOLOG (project DIVA-Jena, 01LC0013). The experiments that were performed for this manuscript all comply with the current laws of Germany.

\section{References}

Behmer ST, Joern A (1993) Diet choice by grass-feeding grasshoppers based on the need for a limiting nutrient. Funct Ecol 7:522527

Behmer ST, Simpson SJ, Raubenheimer D (2002) Herbivore foraging in chemically heterogeneous environments: nutrients and secondary metabolites. Ecology 83:2489-2501

Bernays EA, Bright KL (1993) Mechanisms of dietary mixing in grasshoppers-a review. Comp Biochem Physiol 104:125-131

Bernays EA, Chapman RF (1970a) Experiments to determine the basis of food selection by Chorthippus parallelus (Zetterstedt) (Orthoptera: Acrididae) in the field. J Anim Ecol 39:761-775

Bernays EA, Chapman RF (1970b) Food selection by Chorthippus parallelus (Zetterstedt) (Orthoptera: Acrididae) in the field. J Anim Ecol 39:383-394

Bernays E, Chapman RF (1994) Host-plant selection by phytophagous insects. Chapman and Hall, New York

Bernays EA, Bright KL, Gonzalez N, Angel J (1994) Dietary mixing in a generalist herbivore: tests of two hypotheses. Ecology 75:1997-2006

Bernays EA, Angel JE, Augner M (1997) Foraging by a generalist grasshopper: the distance between food resources influences diet mixing and growth rate (Orthoptera: Acrididae). J Insect Behav 10:829-840

Berner D, Blanckenhorn WU, Körner C (2005) Grasshoppers cope with low host plant quality by compensatory feeding and food selection: N limitation challanged. Oikos 111:525-533

Chapman RF, Joern A (eds) (1990) Biology of grasshoppers. Wiley, New York

Connolly J (1986) On difficulties with replacement-series methodology in mixture experiments. J Appl Ecol 23:125-137

de Wit C, van den Bergh J (1965) Competition between herbage plants. Neth J Agric Sci 13:212-221

Dopman EB, Sword GA, Hillis DM (2002) The importance of the ontogenetic niche in resource-associated divergence: evidence from a generalist grasshopper. Evolution 56:731-740

Freeland WJ, Janzen DH (1974) Strategies in herbivory by mammals, the role of plant secondary compounds. Am Nat 108:269-289

Gardiner T, Hill J (2004) Feeding preferences of Chorthippus parallelus (Orthoptera: Acrididae). J Orthopteran Res 13:197203

Hägele BF, Rowell-Rahier M (1999) Dietary mixing in three generalist herbivores: nutrient complementation or toxin dilution? Oecologia 119:521-533

Hector A, Bazeley-White E, Loreau M, Otway S, Schmid B (2002) Overyielding in grassland communities: testing the sampling effect hypothesis with replicated biodiversity experiments. Ecol Lett 5:502-511

Hellmann JJ (2002) The effect of an environmental change on mobile butterfly larvae and the nutritional quality of their hosts. J Anim Ecol 71:925-936

Hooper DU (1998) The role of complementarity and competition in ecosystem responses to variation in plant diversity. Ecology $79 \cdot 704-719$
Ingrisch S, Köhler G (1998) Die Heuschrecken Mitteleuropas. Die Neue Brehm-Bücherei Westarp Wissenschaft, Magdeburg

Joern A (1996) Host plant quality and grasshopper populations. In: Cunningham GL, Sampson MW, Coordinators T (eds) Grasshopper integrated pest management user handbook, vol technical bulletin no. 1809. United States Department of Agriculture, Washington DC, pp IV.4-1-IV.4-6

Kaufmann T (1965) Biological studies on some Bavarian Acridoidea (Orthoptera), with special reference to their feeding habit. Ann Entomol Soc Am 58:791-801

Köhler G (2001) Fauna der Heuschrecken (Ensifera et Caelifera) des Freistaates Thüringen. Thüringer Landesanstalt für Umwelt und Geologie, Jena

Köhler G, Renker C (2004) Zur Heuschreckenfauna (Ensifera, Caelifera) extensiv genutzter Gerbirgsmähwiesen im Thüringer Schiefergebirge und im Frankenwald (BIOLOG-Flächen). Veröff Naturkundemus Erfurt 23:115-121

Lee KP, Behmer ST, Simpson SJ, Raubenheimer D (2002) A geometric analysis of nutrient regulation in the generalist caterpillar Spodoptera littoralis (Boisduval). J Insect Physiol 48:655-665

Lee KP, Raubenheimer D, Simpson SJ (2004) The effects of nutritional imbalance on compensatory feeding for cellulosemediated dietary dilution in a generalist caterpillar. Physiol Entomol 29:108-117

Loreau M, Hector A (2001) Partitioning selection and complementarity in biodiversity experiments. Nature 413:548-548

Marsh KJ, Wallis IR, Andrew RL, Foley WJ (2006) The detoxification limitation hypothesis: where did it come from and where is it going? J Chem Ecol 32:1247-1266

Miura K, Ohsaki N (2004) Diet mixing and its effect on polyphagous grasshopper nymphs. Ecol Res 19:269-274

Miura K, Ohsaki N (2006) Examination of the food processes on mixed inferior host plants in a polyphagous grasshopper. Popul Ecol 48:239-243

Mody K, Unsicker SB, Linsenmair KE (2007) Fitness related dietmixing by intraspecific host-plant-switching of specialist insect herbivores. Ecology 88:1012-1020

Pfisterer AB, Diemer M, Schmid B (2003) Dietary shift and lowered biomass gain of generalist herbivore in species-poor experimental plant communities. Oecologia 135:234-241

Pulliam HR (1975) Diet optimization with nutrient constraints. Am Nat 109:765-768

Rapport DJ (1980) Optimal foraging for complementary resources. Am Nat 116:324-346

Raubenheimer D, Simpson SJ (1999) Integrating nutrition: a geometrical approach. Entomol Exp Appl 91:67-82

Roscher C, Temperton VM, Scherer-Lorenzen M, Schmitz M, Schumacher J, Schmid B, Buchmann N, Weisser W, Schulze ED (2005) Overyielding in experimental grassland communities-irrespective of species pool or spatial scale.. Ecol Lett 8:576-577

Scriber JM, Slansky FJ (1981) The nutritional ecology of immature insects. Annu Rev Entomol 26:183-211

Singer MS, Bernays EA, Carriere Y (2002) The interplay between nutrient balancing and toxin dilution in foraging by a generalist insect herbivore. Anim Behav 64:629-643

Sword GA, Dopman EB (1999) Developmental specialization and geographic structure of host plant use in a polyphagous grasshopper, Schistocerca emarginata (=lineata) (Orthoptera: Acrididae). Oecologia 120:437-445

Takeuchi M, Kjshikawa H, Tamura M (2005) Host use in relation to food availability and larval development in the specialist herbivore Epilachna admirabilis (Coleoptera: Coccinelidae). Appl Entomol Zool 40:177-184 
Trenbath B (1974) Biomass productivity of mixtures. Adv Agron 26:177-210

Unsicker SB (2006) Plant-insect interactions in grasslands along a gradient of plant species diversity. Ph.D. thesis, Institute of Ecology, University of Jena, Jena, p 113
Werner EE, Gilliam JF (1984) The ontogenetic niche and species interactions in size structured populations. Annu Rev Ecol Syst $15: 393-425$ 